\title{
Personality, Work-Life Balance, Hardiness, and Vocation: A Typology of Nurses and Nursing Values in a Special Sample of English Hospital Nurses
}

\author{
Christopher Bagley ${ }^{1, *}$, Mahmoud Abubaker ${ }^{2,+}$ and Alice Sawyerr ${ }^{3,+}$ \\ 1 Faculty of Social Sciences, University of Southampton, Southampton SO171UN, UK \\ 2 Leeds Business School, Leeds Beckett University, Leeds LS13HE, UK; m.abubaker@leedsbeckett.ac.uk \\ 3 Department of Continuing Education, University of Oxford, Oxford OX12JA, UK; \\ alice.sawyerr@conted.ox.ac.uk \\ * Correspondence: chrisbagley2@gmail.com; Tel.: +44-113-293-3167 \\ + These authors contributed equally to this work.
}

Received: 11 November 2018; Accepted: 1 December 2018; Published: 5 December 2018

check for updates

\begin{abstract}
This initial report of a longitudinal study of 192 English hospital nurses measured Nursing Values (the 6Cs of nursing); Personality, Self-Esteem and Depression; Burnout Potential; Work-Life Balance Stress; "Hardy Personality"; and Intention to Leave Nursing. Correlational, component, and cluster analysis identified four groups: "The Soldiers" $(N=79)$, with medium scores on most measures, who bravely "soldier on" in their nursing roles, in the face of numerous financial cuts to the National Health Service, and worsening nurse-patient ratios; "Cheerful Professionals" $(N=54)$, coping successfully with nursing roles, and a variety of challenges, in upwardly mobile careers; "High Achievers" $(N=39)$, senior nurses with strong profiles of a "hardy personality", and commitment to fundamental nursing values; and "Highly Stressed, Potential Leavers" $(N=20)$, with indicators of significant psychological distress, and difficulty in coping with nursing role challenges. We have initiated a program of co-counselling and social support for this distressed group, by nurses who are coping more successfully with multiple challenges. We discuss the role of nurse educators in fostering nursing values, developing and supporting a "hardy personality" and emotional resilience in recruits to nursing. This study is framed within the disciplinary approach of Critical Realism, which identifies the value basis for research and dialogue in developing strategies for social change. The importance of this research is that: (a) it is part of the new thrust in nursing research, applying Critical Realist theory and methodology to research on nursing stress; (b) it has established, through network sampling, a group of nurses who can be supportive of each other in their stressful careers; (c) it establishes the reliability and potential validity of a measure of core nursing values; (d) it is among the first studies in research on nursing stress, to use the humanizing methodology of moving from data analysis (description of "things"), to describing a typology of nursing stress and career progress (description of individuals).
\end{abstract}

Keywords: nursing values; burnout; hardy personality; work-life balance; nursing stress; co-counselling; critical realism; nurse education; nurse-patient ratios

"Hospitals are institutions cradled in anxiety." (Revans 1996, p. 420)

1. Introduction: A Planned Long-Term Study of Nursing Values, Psychological Strengths, Stress Factors, and Nursing Careers-A Critical Realist Approach

This paper is planned as the first in a series of quantitative and qualitative reports on a group of nurses, from a longitudinal study of personality, stress, values, role performance, and career outcomes 
in groups of hospital nurses. The study is grounded in the research philosophy of critical realism (Bhaskar 2002; Wilson and McCormack 2006; Bagley et al. 2016). Critical realism is a value-based approach which intuitively identifies the ontology or value base of the phenomena examined, creating layers of understanding and analysis through dialogues with, and by, the subjects of study in order to achieve morphogenesis, the constructive dialogue of consciously engineered social change (Archer 2007; Caetano 2015). Critical realism (CR) seeks to understand the "real" nature of social phenomena, and ideally involves a qualitative case study, which can deploy mixed-methods, including use of standardized questionnaires, to elucidate the morphogenetic process, a dialogue for self-awareness, self-regard, and social change (Archer 2007). Critical realism is then, fundamentally a value-based approach to research, and goes beyond hypothesis-testing and positivist models.

Based on our personal assumptions and experiences of nursing as a value-based, highly stressed and often unrewarded profession we develop a heuristic enquiry which seeks: (a) to see, in our "snowball" sample, if the relationships between stressful outcomes and supposed antecedents of stress, are similar to those established in previous research studies of nurses, which have used probability samples, and more positivist notions of research; (b) to explore on the basis of various methodologies both quantitative and qualitative, how relationships between the variables measured can be reduced to a potentially fruitful typology of different types of adjustment amongst the nurses studied; (c) to establish some bases for a co-counselling and mutual support network amongst nurses, to support those undergoing stress; (d) to explore a values base for nursing education, practice, and administration.

Critical Realism seeks on the basis of both an intuitively derived value framework, and a variety of types of evidence, to promote social change in which absences - the hidden parts of systems of oppression, abuse or exploitation are hidden-can be exposed as the basis of morphogenesisis, the dialogue for social change and the confrontation of alienating forces which mask oppression (Alderson 2013, 2015; Sawyerr and Bagley 2017). A fuller account of general principles of critical realist methodologies is given in Bagley et al. (2016). Critical realism is seen as a valuable research approach in the study of institutions, and of groups of students and workers (including nurses), experiencing stress and change (Bhaskar 2002; McEvoy and Richards 2003; Wilson and McCormack 2006; Walsh and Evans 2014; Schiller 2016; Williams et al. 2017; Allmark and Machaczek 2018). Critical realism in nursing research is par excellence a methodology "for emancipatory practice" (Parlour and McCormack 2012).

Our first research task in the critical realist research journey has been to explore, in an opportunistic sample of research subjects gathered through the "snowball" methodology, to replicate previous work in which a variety of stress factors, and their antecedents, may be significantly correlated. If the correlations we obtained were similar to those of previous research, then we have some indicators of reliability and validity of the basic parameters. We also introduce at the outset a new measure, of Nursing Values, attempting to establish the reliability of this instrument before exploring its correlation with other measures. Findings on the reliability and implications of the Nursing Values Scale (NVS) are presented before the further measures and their usefulness in research on nursing stress are described, since we argue that the NVS is merely one of a number of variables which may have importance in establishing a typology of nurses' stress and achievement.

\section{The Initial Model Explored}

This study is exploratory and descriptive, but with an element of action research. The model initially explored was that commitment to Nursing Values would be predicted by or at least would correlate significantly with personal strengths such as high self-esteem, certain personality factors, and a "hardy personality" profile; with psychological discomfort such as depression, neuroticism, and social stressors such as Work-Life Balance (WLB) issues; and work stress as indicated by the measure of potential burn-out. A further question was explored-if diminished commitment to nursing values predicted intention to leave nursing, would the significance of that prediction survive when other variables in the study were controlled for in a standard regression analysis? A further 
aim has been to identify sub-groups within our cohort of nurses, such as those with special strengths, and those who are vulnerable to stress of various kinds.

\subsection{Nursing Values}

Nursing, we argue is a profession which calls for a special kind of person, whose personality and personal values may help them cope with demanding roles as key providers of medical care. The values of a nurse's calling are epitomized by "the 6Cs of nursing" (Cummings and Bennett 2012; NMC 2015). These are: Care, Compassion, Competence, Communication, Courage, and Commitment.

The origin of these six values seems to be British and were operationalized in recent times for all National Health Service hospital staff guidance and achievement, by the United Kingdom's Department of Health (Clarke 2014; Stephenson 2014). But the values have a decidedly "Nightingalean" ring, reflecting the pioneering work of Florence Nightingale, who developed humane and efficient nursing care practices (Spurlock 2017). There is a clear connection in nurse populations between strongly held professional values, "personal dignity", and professional self-esteem (Sturm and Dellert 2016).

\subsubsection{Care}

Care is at the core of the nurse's role, the nurse being the carer and comforter of individuals undergoing stressful (and sometimes joyous) life changes, including injury, life-saving treatment, birth, recovery, rehabilitation, end of life care, and ease in dying.

\subsubsection{Compassion}

Compassion includes both inherent and acquired personality traits of intelligent and empathic identification of each patients' fears, anxieties, sufferings, and hopes.

\subsubsection{Competence}

Competence involves acquiring the technical skills of being able to nurse well, and to integrate with and sometimes manage complex tasks in medical care teams, optimizing personal professional talents; and the mastery, application and integration of new techniques and technologies.

\subsubsection{Communication}

Communication involves listening and talking to others-patients and colleagues-and communicating one's own needs and understandings of patient care to colleagues and to line managers, and openly offering support to both colleagues and patients in stressful situations.

\subsubsection{Courage}

Courage involves steadfastness in the face of stressful situations and in coping with the suffering of others, with the courage to think of and implement new ways of optimizing patient care, as well as overcoming the stress of identifying with the personal pain and grief of some patients, in positive ways.

\subsubsection{Commitment}

Commitment involves a dedication not only to patients, but also to understanding and applying new skills and forms of technology, as well as a commitment to understanding the organization in which one works, enabling through insightful understanding the smooth running of this organization.

\subsection{Importance of Values in Nursing}

Nursing educators in North America and the UK have consistently argued and shown in research studies, that a coherent framework of values such as the 6Cs may assist in the performance of roles which are often difficult and challenging: however, scholars are in agreement that more research is needed to discover methods that may be used to promote and support professional 
values among nurses already practicing clinically (Day et al. 2017; Sibandze and Scafide 2017; Gottlieb and Gottlieb 2017).

Newly graduating nurses may have their idealistic values about nursing crushed by hospital bureaucracies, especially when nurse-patient ratios are poor, and the anxiety-laden culture of the hospital fails to support this devoted section of its staff (McSherry et al. 2012; Maben et al. 2006; Gottlieb 2013). For these reasons, nurse educators have argued that in their undergraduate education, nurses should "anchor and internalize" a set of basic values which will support them during the stresses of a nursing career that they will inevitably face (Day et al. 2017).

\section{Stresses Faced by Nurses, and Some Consequences of Stress}

Nurses need all of the qualities described in the 6Cs in surviving in a difficult and demanding profession, especially when their professional roles are undermined by relatively low pay, as in the United Kingdom. Furthermore, recent failure to fund nurse training places in colleges and universities in the UK has meant that nurse-patient ratios have steadily declined (RCN 2017; Francis 2013; Ball and Pike 2009). By 2018, more nurses were leaving the profession in England than were joining, the majority of leavers being aged less than 50 (Triggle 2018). Over two years there had also been a decline of one-third in numbers entering a nursing degree and other nurse training courses (Marsh 2018). It appears that there has been a "downward spiral": as nurse-patient ratios worsened, the job of nursing has become more stressful and increasing numbers have left the profession.

The problems facing nurses in their demanding roles which may lead to profound psychological distress, burnout, and even suicidal behavior have been described in different cultures, regardless of models of health care delivery (Adriaenssens et al. 2015; Akerboom and Maes 2006; De Boer et al. 2011; Bruyneel et al. 2016). American research too has clearly shown the negative, downward spiral that poor nurse-patient ratios in hospitals can set in train. Overworked nurses caring for many patients are unable to use their professional skills adequately, leading to disenchantment with nursing, increase in anxiety and depression, burnout, and leaving the profession (Edwards 2001; Browning et al. 2007; Coomber and Barriball 2007).

This work has been replicated with large populations of nurses in Europe and the United Kingdom showing that, as in the United States, poor nurse-patient ratios are associated with higher rates of patient morbidity—new illnesses acquired while in hospital; and mortality—deaths to due to poor care, or to "tasks left undone" (Aiken et al. 2008, 2014; Griffiths et al. 2016).

Nurses themselves have significantly elevated rates of completed suicide compared with females in other professions (Anderson et al. 2015) - this may be due to their greater access to lethal substances (Kôlves and De Leo 2013). Although completed suicide is relatively rare in populations of nurses, there is clearly a population of nurses enduring depression, suicidal ideation, and other indicators of psychological distress at rates which significantly exceed those in their age peers in non-medical professions (De Boer et al. 2011).

Career nurses also have to face the challenge of work-life balance (WLB), when the individual's social and family life is challenged by the demands of their work roles, including having to work long shifts, some of them as night duty (Cortese et al. 2010). For this reason, we have included a measure of WLB stress in our measurement package, since hypothetically WLB stresses may interact with or exacerbate nursing role stress. This is a surprisingly under-researched area in nursing research (Düchting 2015).

There is an additional literature on psychological resilience in nurses and other human service workers, showing that some individuals have special strengths in coping with stress and professional challenge (Dewe and Cooper 2017). The "resilient nurse" is, on the "Big Five" personality profiles, likely to be emotionally stable, outgoing, and communicative (Judge et al. 2002; Bruck and Allen 2003; Törnroos et al. 2013). However, this important issue of resilience, and how nurses may be supported or assisted in developing resilience, has a relatively sparse body of research literature. Because of the potential importance of various personality factors in creating resistance to stress in various 
occupational groups (Törnroos et al. 2013; Judge et al. 2002; Bruck and Allen 2003; Bakker et al. 2006) we have included the measure of the American "Big 5" personality profiles, which are valid and reliable measures across cultures (McCrae et al. 1999), in the present study of British nurses.

No specific hypotheses have been formulated in this exploratory study, although we did expect to find links between important variables such as personality, adjustment, mental health, work-life balance stress, burnout potential, desire to leave nursing, a hardy or resilient personality, and nursing values, which were consistent with those of previous work. Ours is the first study to combine all of these variables, which have been measured as the basis for longitudinal work predicting adjustment to nursing roles, and ways in which nurses under stress can be supported by collegial, peer support.

\section{The Study Population and Interview Procedures}

Nurses are most easily accessed for questionnaire completion during their college studies, and afterwards during post-qualification training workshops. Accessing nurses in their workplaces is difficult, since many employers will not allow researchers to have access to their already overtaxed nursing staff; and approaches for participation using employment channels seem to yield a less than 60 percent response rate (Adriaenssens et al. 2015). Heinen et al. (2013) reported that in England, mailed questionnaires using hospital employment records yielded only a 39 percent response. Another method is to use the professional register of nurses, sending questionnaires to listed addresses. But this is problematic since many addresses are out of date, and responses using this method can be as less than 50 percent (Edwards 2001).

The method we have used in the present work is that of "snowball sampling", an established methodology in social and nursing research (Sadler et al. 2010; Heckathorn 2011; Kandola et al. 2014). The snowball sample acquires respondents as a rolling snowball collects snow, each contacted individual recommending one or more professional colleagues who might be interviewed. The sample acquired represents a non-random group of nurses, but comparative work suggests that this method yields a higher proportion of acquiescent subjects, and also gives information that is representative and valid, and at least as complete as that obtained through probability (random) sampling (Kandola et al. 2014; Valerio et al. 2016).

The initial persons (accessed through our own personal contacts) interviewed were asked to name people (other nurses) working in hospitals whom we might contact in order to invite them to complete the questionnaire. We were thus able to make contact with 210 female nurses, 192 of whom (91\%) finally completed the whole questionnaire-an excellent response rate compared with studies of nurses using other research methods. Each person contacted was given a $£ 10$ retail store voucher, regardless of whether or not they finally completed the questionnaires. The female nurses lived in the north of England, in the urban regions of Liverpool and Manchester. We chose not to interview male nurses at this stage, in order to gain a gendered, homogenous group.

The biases introduced by snowball sampling (obtaining a subgroup for study who may share the same interests and experiences) must be judged against more formal studies of UK nurses, which have only achieved successful response rates of between 39 and 49 percent (Edwards 2001; Heinen et al. 2013). Our initial sample consisted of six relatively senior nurses known to us professionally, each of whom then nominated two or more likely candidates for the study, as did the majority of the nurses successfully interviewed in the "snowball" network (often we were referred to nurses who were already in the sample). One bias in our sample is that through our initial selection of six successful nurses, we would be referred to a professionally successful group of nurses, who were not struggling in their professional roles. We note, however, that we did identify in this network a group of nurses ( $12 \%$ of the sample) who declared an intention to leave nursing, compared with the 10 percent of English nurses in the probability sample of Heinen et al. (2013).

The average age of the nurses we contacted was 36.5 years (range 24 to 55 years), and all had professional qualifications in nursing: 87 with three or four year degree training; 100 with three-year training to become state registered nurses; and 5 with two-year training to become state 
enrolled nurses; 37 had additional training, diplomas or certificates in midwifery, children's nursing, psychiatry, orthopedics, theatre nursing, or other specialties, and all worked between 20 and $40 \mathrm{~h}$ a week, in National Health Service hospitals. Nearly two thirds (65\%) had either a partner, children, or both, and 50 percent had a dependent child $(<19)$ or adult in their household, who relied on them for care. Forty percent held positions of relative seniority, beyond that of staff nurse. Our method of sampling meant that we contacted women who were active in their nursing roles, so we did not reach those who had already left the profession for any reason. The snowball method did introduce the bias that we were studying women who often knew one another, were often at similar stages of their careers, and likely shared some of the same interests and values.

Respondents completed the questionnaire on a laptop computer in a variety of settings, while the researcher was close by, answering any queries. Ethical procedures required us to refer for specialist help any individual whom test results, or personal accounts indicated significant psychological stress. We offered all of those interviewed strict confidentiality of the interview questionnaire findings, but with the option to allow us to contact them in follow-up work. Ten nurses $(5 \%)$ requested that we should not contact them again. A small number of individuals began answering the laptop-programmed questions, but at some stage declined to complete the questionnaires: they were not included in the study, and in the final count 192 nurses completed all the questionnaires.

In addition, we asked those nurses who completed the questionnaires, and had been in post for at least five years, whether they were interested in being trained as telephone counsellors for any of their professional peers who were experiencing difficulties in their professional roles, and in the area of work-life stress. After considering the qualifications of the volunteers, and their own manifest psychological stability and "hardiness", we recruited a core group of 20 peer counsellors. A report on peer-to-peer counselling and support will be the topic of a subsequent paper.

\section{Instruments and Questionnaires}

First, a general questionnaire was completed concerning work history, periods away from nursing, other qualifications, reasons for choosing the nursing profession, and any plans for leaving nursing. ${ }^{1}$ Then respondents completed the six-item scale seeking endorsement of the $6 \mathrm{C}$ Values of nursing (Table 1). We acknowledge that the instrument as designed, invites a positive response set: we thought it ethical at the outset to stress the positive and salient nature of these core nursing values. What we were examining was the degree to which the nurse respondents were not completely confident in the endorsement or application of these values.

Other measures completed were:

\subsection{Maslach's Burnout Inventory}

Maslach's Burnout Inventory, which has been used in studies of nurses' and other professionals' career patterns in order to assess diminished morale due to job stress (Maslach and Jackson 1986; Maslach et al. 2001, 2006). This 20-item scale has identified the potential for nurses suffering "burnout" — exhaustion, role disenchantment, imminence of leaving nursing, frequent sickness, and automated or depersonalized performance of routine duties. It has three subscales, "Emotional exhaustion" (e.g., of item "I feel emotionally drained from my work"); "Depersonalization" (e.g., of item "I don't really care what happens to some patients"); and "Personal accomplishment" (e.g., of item "I deal effectively with the problems of my patients" — scored negatively) (Rich and Rich 1987). The scale is valid and reliable in studies of nurses in a variety of cultural settings (Van Bogaert et al. 2009a, 2009b; Pisanti et al. 2013). There is some evidence that susceptibility to

1 Ethnicity and country of origin were measured in various ways but did not correlate significantly with any of the other variables deployed. 
burnout is influenced by pre-existing personality variables (Langelaan et al. 2006), so it has been useful to covary personality with burnout measures.

\subsection{The Short Hardiness Inventory}

The Short Hardiness Inventory which has been developed by Bartone et al. (2008) from the work of Kobasa et al. (1982) to explain why some individuals in stressful conditions such as military combat, survive with and without mental health problems such as depression, anxiety, and post-traumatic stress. The measure is also valuable in measuring various kinds of motivation in the face of potentially stressful challenges (Benishek and Lopez 2001). Bartone et al. (2008) found that: "Hardy persons have a high sense of life and work commitment, greater sense of control, and are more open to challenges in life" (p. 80). The 15-item measure (e.g., of item "Stressful life events give me interesting opportunities for growth") correlates positively with various kinds of role achievement, good psychological health following stress, good self-concept in role performance, and inversely with a global measure of depression. The three sub-scales in the Hardiness Inventory (control, commitment, challenge) are strongly intercorrelated so we have combined them into a single scale. We speculate that "hardiness" is a valuable facet of personality for career nurses, as Rich and Rich (1987) had argued in writing about a group of American nurses, and as Garrosa et al. (2008) have shown in a more recent study.

\subsection{The 'Big 5' Personality Inventory}

The "Big 5" Personality Inventory is now accepted as the standard measure of personality, and validity and reliability have been established in many studies, including work with translated versions of the scale in a variety of cultures (McCrae et al. 1999; Soto et al. 2011).

The five personality dimensions which emerged from the factor analytic studies of McCrae et al. (2008) are:

\subsubsection{Agreeable}

Agreeable: wishes of others are always considered, modest, co-operative rather than competitive, not inclined to argue or disagree — and the polar opposite of these traits (e.g., of item "I see myself as a person who is helpful and unselfish to others").

\subsubsection{Openness to Experience}

Openness to Experience: curious, artistic, novelty seeking, intuitive, emotionally reactive versus being pragmatic, and evidence-based individuals (e.g., of item "I see myself as a person who values artistic, aesthetic experience").

\subsubsection{Extraversion}

Extraversion: outgoing, energetic, strong and usually positive emotional reactions, sociable, seeking social stimulus in the company of others-socially active and attention-seeking at one extreme, versus being reserved, shy, withdrawn, self-absorbed, and avoiding social interactions, at the other extreme (e.g., of item "I see myself as a person who is sometimes shy and inhibited").

\subsubsection{Neuroticism}

Neuroticism: secure and confident individuals who are stable, calm, and unworried versus individuals who are nervous, often worried, anxious, and depressed (e.g., of item "I see myself as a person who is emotionally stable, not easily upset").

\subsubsection{Conscientiousness}

Conscientiousness: self-disciplined individuals who strive for achievement in meeting external goals, with the ability to control or regulate their impulses with planned rather than spontaneous 
behavior, versus the polar opposite, of individuals who do not plan ahead, and may be disorganized in their behavioral patterns (e.g., of item "I see myself as a person who does a thorough job"). The scales are measured on a 5-point parameter from "strongly disagree (1) to "strongly agree" (5), with reverse scoring as necessary.

Responses to the NEO (Neuroticism-Extraversion-Openness) Personality Questionnaire fit the normal curve, so some 68 percent of respondents (i.e., those scoring in the one standard deviation range around the population mean) do not score at the extremes of the five personality dimensions-thus, the average person for example, is neither introverted nor extraverted. There are small but significant correlations between the five dimensions, in theoretically expected directions (McCrae et al. 2008), so new studies using the NEO questionnaire must explain any deviation from previously observed patterns (McCrae et al. 1999). A review of 163 studies linking Big 5 scores to "job satisfaction" (Judge et al. 2002) showed that in combination the five profiles of personality correlated on average, at 0.41 with various measures of job satisfaction.

In studies with nurses and others who engage in work with ill or distressed people, higher Extraversion and lower Neuroticism scores were the most salient in predicting lack of Burnout potential on the Maslow scales (Adriaenssens et al. 2015; Törnroos et al. 2013).

Genetic studies following twins into adulthood indicate that around half of the variance in the five NEO scores has a hereditary basis (Jang et al. 1996), so these personality dimensions are likely to be stable and enduring factors in an individual's temperament, rather than primarily being due to environmental or stress factors. It is possible however that individuals who have salient personality characteristics may react to stress in distinctive ways. Thus, nurses who are both introverted and neurotic (scoring beyond the one standard deviation range) might handle stress poorly (Adriaenssens et al. 2015). Whether scores on measures of personality and social adjustment precede (as a risk factor), or are caused by stress factors, or is due to statistical interaction effects, is not clear from the published literature.

\subsection{The Center for Epidemiological Studies of Depression (CES-D) Questionnaire}

This measure, developed by Radloff (1977), is a widely used and well-validated 20-item measure of classical signs of depression, and a score of 16 or more on the scale (theoretical range 0 to 60 ) indicates a strong likelihood that an individual has a depression which merits investigation and treatment (Knight et al. 1997). The questionnaire asks about feelings in the past week (e.g., "I felt depressed") on a scale ranging from 0 (not at all) to 3 (most days or all of the time).

\subsection{The Rosenberg Self-Esteem Inventory (RSEI)}

There is surprisingly little research on the self-esteem of nurses as a professional group (Sturm and Dellert 2016). The only relevant study that we can find using the Rosenberg Scale-our preferred measure-is by Peterson-Graziose et al. (2013), which showed that poorer levels of self-esteem predicted attrition of American nurses from Associate Degree programmes. Evidence reviewed by Sawyerr and Bagley (2017) shows that the widely-used, valid, and reliable RSEI is socially constructed, through the individual's socialization and social interactions, and from early adolescence becomes a strong basis for inner-strength and self-confidence in meeting the stresses of life. This evidence shows that by young adulthood, self-esteem has become a core part of personality, and is difficult to modify. In the tables below, higher RSEI score indicates better self-esteem.

\subsection{Hayman's Measure of Stress Linked to Work-Life Balance (WLB) Problems}

Stresses due to the imbalance between work outside of the home, and commitments to family and vocational pursuits other than in the field of paid work, has only been properly recognized in the past two decades, and indeed feminist critics argue that women are frequently disadvantaged in the workplace because the demands in a largely sexist society, of having to "care for" husband and children-which add to stresses imposed by professional work, such as nursing (Boyar et al. 2007; 
Cortese et al. 2010; Törnroos et al. 2013; Y1lmaz et al. 2017). We chose Hayman's (Hayman 2005, 2009) scale as showing good evidence of discriminant validity. The measure includes three sub-scales, but since the third sub-scale measured a different dimension of work-life balance, we have combined the first two strongly correlated sub-scales (personal life interfering with work performance; and work roles undermining enjoyment of personal life) into a single measure, which has high alpha reliability (e.g., of items "I neglect personal needs because of the demands of my job"; "My work suffers because of the demands of my personal life"). Scoring is on a 7-point Likert scale, and a high score indicates greater amounts of stress due to work-life imbalance. The factorial validity of the three dimensions of WLB stress in nurse educators has been established by Smeltzer et al. (2016).

\subsection{Intention to Leave}

Intention to Leave was measured by responses to the questions (Li et al. 2011): “Do you plan to leave nursing permanently within the next 12 months? (No, Unsure, Yes); "Even if you have no plans to leave the nursing profession, would you leave if alternative employment became available?" (No, Unsure, Yes). Twelve percent planned to leave nursing, and an additional 10 percent would leave if they had an alternative. In the correlational analysis reported below, only active intention to leave was used.

\subsection{Seniority in Nursing}

Seniority in nursing was measured as: $0=$ basic grade nursing (e.g., staff nurse) $15 \% ; 2=$ senior staff; 3 = nurse/charge nurse $45 \%$; clinically specialized / executive role $40 \%$.

\subsection{Issues of Response Set and Problems of Validity}

The Nursing Values Survey invites response set, in that we invite positive responses (agreement with), and positive answers about personal commitment to each of the six facets of professional values in nursing. Respondents answered this questionnaire first, and this may have influenced their responses to subsequent questions, focusing the nurses on presenting themselves, professionally and personally, in the best possible light-as they would like to be, rather than as they "actually" are. If this bias has occurred, then correlations with indicators of distress, alienation from nursing, burnout, depersonalization, and desire to leave nursing may have been underestimated. In addition, curtailing statistical variance in this type of response set may be an artefact working against significance in the correlations obtained.

In the longitudinal research planned we are also creating an experimenter effect, in that we are committed to alleviating psychological distress, as well as attempting to support nurses who are contemplating leaving the profession. We describe our cohort of nurses as "special" since we are potentially creating a particular consciousness, an enhanced set of values concerning self and others. Nevertheless, we hope that our approach can be an exemplar for practice by professional nurse managers and educators.

\section{Findings: The Nursing Values Scale (NVS)}

The NVS (Table 1) follows a simple format, restating each basic value, and asking respondents the extent to which they applied or followed each value in their practice. A quarter of nurses responded "All of the time" to all six of the values, while only seven individuals responded "Unsure" or "Rarely" to all six. 
Table 1. The six-item measure of basic nursing values.

\begin{tabular}{|c|c|c|}
\hline $\begin{array}{l}\text { To What Extent Do You Apply or Follow These "Basic } \\
\text { Nursing Values" in Your Work? (All of the Time = } \\
\text { 1/Some of the Time = 2/Unsure = 3/Rarely =4) }\end{array}$ & $\begin{array}{l}\text { Mean } \\
\text { (Standard } \\
\text { Deviation) }\end{array}$ & Loading on General Factor \\
\hline Caring as a core part of my nursing role & $1.85(1.1)$ & 0.72 \\
\hline Compassion in identifying patients' needs & $2.40(1.9)$ & 0.51 \\
\hline Competence in acquiring \& applying professional skills & $1.93(1.6)$ & 0.69 \\
\hline Communication with patients and colleagues & $2.22(1.7)$ & 0.53 \\
\hline Courage in dedicating myself to the nurse's role & $2.42(1.8)$ & 0.48 \\
\hline Commitment in dedication to patients & $1.82(1.6)$ & 0.65 \\
\hline Scale total & $12.64(3.6)$ & $\begin{array}{l}\text { General factor (Eigen } 5.76 \text { ) } \\
\text { explains } 67 \% \text { of variance in } \\
\text { correlations between } 6 \text { items }\end{array}$ \\
\hline
\end{tabular}

The scale has good internal reliability (Alpha 0.91), reflecting a strong general factor in a principal components analysis.

\section{Findings: Correlation of Variables, and Prediction of Nursing Values and of Intention to Leave}

Inspection of the correlation matrix shows that the highest correlations are those between Depression, Self-Esteem, and Neuroticism, with smaller but significant correlations of these three salient variables with many of the other measures, including the Burnout Scales, Hardy Personality, Nursing Values, and Intention to Leave. Since we were particularly interested in correlations which could offer some evidence of face validity, in terms of correlation with established scales with known criteria of external validity, for the Nursing Values Scale (NVS) we list these correlations in Tables 2 and 3, along with correlations of Intention to Leave Nursing, another key variable.

Higher scores on the NVS were significantly associated with having a Hardy Personality, Good Self-Esteem, being in a Higher Ranked Job, not Intending to Leave Nursing, being Conscientious and Agreeable, not being Depressed or Neurotic, and having lower scores on the Burnout sub-scales. While this offers some evidence of construct or face validity, nevertheless even when the effect of all of these variables was combined in a regression equation (in which no particular hypothesis was tested, and variables entered according to the strength of their original correlation with the dependent variable), the final correlation of 0.39 explained only 15.2 percent of the variance in the NVS scale. Two possible reasons for this are that the NVS imperfectly measures the values construct; and there are other relevant variables which we have not been included in our study, which might explain additional variance in NVS scores.

The simple statement of intention to leave nursing within a year was normalized as a measure for correlation analysis, and interestingly had a number of variables significantly associated with it, but in an obverse manner compared with the correlations with the Values scale. Intention to Leave was predicted with statistical significance by: being younger, having lower job rank, being more depressed and neurotic, with lower self-esteem, lacking a Hardy Personality, having higher scores on the Burnout Scales, experiencing Work-Life Balance stress, being less Extraverted and Agreeable, and showing somewhat less attachment to basic Nursing Values. However, when these variables were controlled on one another in a regression analysis, Nursing Values failed to be a significant predictor of intention to leave, while the combination of a lack of Hardy Personality traits, Depression, depersonalization on the Burnout scale, poorer self-esteem, and being Introverted rather than Extraverted, remained significant predictors of Intention to Leave, but in combination explained only 10 percent of the variance in the Intent to Leave measure. 
Table 3. Correlations of Nursing Values Scale, and intention to leave nursing, with results of regression equations for each predicted variable.

\begin{tabular}{lcc}
\hline \multicolumn{1}{c}{ Variable } & Nursing Values Scale & Intention to Leave Nursing \\
\hline Hardy Personality & 0.36 & -0.15 \\
Good Self-Esteem & 0.36 & -0.29 \\
Extraversion & 0.31 & -0.27 \\
Conscientiousness & 0.31 & -0.06 \\
Burnout 2 (Depersonalized) & -0.30 & 0.30 \\
Job rank (low to high) & 0.29 & -0.20 \\
Agreeableness & 0.28 & -0.19 \\
Depression & -0.27 & 0.29 \\
Neuroticism & -0.26 & 0.27 \\
Burnout 1 (Emotional Exhaustion) & -0.25 & 0.30 \\
Open to Experience & 0.24 & 0.02 \\
Burnout 3 (Achievement Failure) & -0.23 & 0.30 \\
WLB Stress & -0.06 & 0.28 \\
Intention to Leave Nursing & -0.30 & 1.00 \\
Combined predictor variables & 0.39 (15.2\% of variance: Hardy hi + & 0.32 (10.0\% of variance: Hardy lo + \\
significant after step-wise & Self Esteem hi + Neuroticism lo + & Depression hi + Burnout 2 hi + \\
regression & Extraversion hi) & Self Esteem lo + Extraversion lo) \\
\hline Nursing Values Scale correlation & & -0.13 (NS) \\
with Intention to Leave, after & & \\
stepwise multiple regression & & \\
\hline \multicolumn{2}{l}{ Significance: Correlations of 0.15 and above are significant at the 5\% level or beyond. Significance of combined } \\
predictor variables: 0.001\% level for Nursing Values; and 0.005\% for Intention to Leave.
\end{tabular}

\section{Component and Cluster Analysis to Identify Groups of Individuals}

In this exploratory study, we are interested to see if our sample of nurses can be classified into different groups, who might require different kinds of support in their professional lives. To explore this, we used programs in the SPSS-16 package which first of all classified selected variables in a principal component analysis, calculating factor scores on each component for each individual, these scores then being used as the basis for cluster analysis of individuals. In sociological research, component analysis can flow logically into cluster analysis which identifies groups of individuals from clustering of variables (Bailey 2012; Mokhtarian et al. 2012; Hillege et al. 2017). This process "humanizes" data analysis in identifying groups of individuals rather than focusing on a set of reified variables (Bailey 2012; Hacking 2012). Cluster analysis is the final technique for "bringing people back in" after complex types of data analysis leaves the researcher "swamped" with a set of complex covariants (Byrne and Uprichard 2012).

After an initial factor analysis, we specified a 3-factor, orthogonal solution (i.e., required each rotated component to be independent, with vectors at right-angles with $\sin$ values of zero.) This solution was specified after an initial calculation of seven oblique factors which accounted for just over 50 percent of the total variance in the intercorrelation matrix. This intuition proved fruitful, and four distinct and heuristically useful clusters have emerged accounting for 54 percent of the variance in a truncated list of variables, in which the three Burnout scales were merged into a single scale (Tables 4 and 5). Table 6 presents a typology of nurses, based on cluster analysis of the principal component scores for each individual. The basis for the fourfold typology is that it is both heuristically meaningfully, and maximizes the "statistical distance" between individuals, on the various measures employed. 
Table 4. Principal components analysis of selected variables.

\begin{tabular}{lccc}
\hline & I & II & III \\
\hline Job rank (low to high) & 0.59 & 0.05 & 0.40 \\
Neuroticism & -0.65 & 75 & 0.02 \\
Extraversion & 0.46 & 0.17 & 0.57 \\
Openness to Experience & 0.11 & 0.26 & -0.15 \\
Agreeableness & 0.48 & -0.37 & 0.44 \\
Conscientiousness & 0.14 & 0.22 & -0.13 \\
Hardy Personality & 0.63 & -0.46 & 0.60 \\
Depression & -0.52 & 0.67 & -0.31 \\
Self-Esteem (low to high) & 0.63 & -0.46 & -0.28 \\
Burnout Scales combined & -0.47 & 0.58 & 0.15 \\
Work-Life Balance stress & -0.32 & 0.20 & -0.41 \\
Intention to Leave Nursing & -0.49 & 0.01 & 0.14 \\
Nursing Values Scale & 0.27 & 0.07 & 0.40 \\
Eigen Value & 3.13 & 2.61 & 2.00 \\
Cumulative \% of variance accounted for & $34 \%$ & $45 \%$ & $54 \%$ \\
\hline
\end{tabular}

Note: Principal components analysis used Varimax rotation, requiring orthogonal vectors.

Table 5. Cluster analysis of 192 nurses, using factor scores from the principal components analysis.

\begin{tabular}{|c|c|c|c|c|c|}
\hline & A (79) & B (54) & $C(20)$ & D (39) & Chi-Squared Values \\
\hline Job rank high & $13 \%$ & $31 \%$ & $6 \%$ & $49 \%$ & $36.71(6 \mathrm{df}) p<0.0000$ \\
\hline Job rank low & $17 \%$ & $7 \%$ & $20 \%$ & $4 \%$ & \\
\hline Intention to leave nursing & $15 \%$ & $9 \%$ & $80 \%$ & $3 \%$ & $65.15(3 \mathrm{df}) p<0.0000$ \\
\hline Neuroticism hi quartile & $25 \%$ & $26 \%$ & $37 \%$ & $12 \%$ & $86.41(6 \mathrm{df}) p<0.0000$ \\
\hline Neuroticism lo quartile & $25 \%$ & $23 \%$ & $2 \%$ & $50 \%$ & \\
\hline Extraversion hi quartile & $15 \%$ & $31 \%$ & $6 \%$ & $48 \%$ & $46.23(6 \mathrm{df}) p<0.0000$ \\
\hline Extraversion lo quartile & $33 \%$ & $30 \%$ & $17 \%$ & $20 \%$ & \\
\hline Agreeableness hi quartile & $27 \%$ & $32 \%$ & $10 \%$ & $31 \%$ & $20.87(6 \mathrm{df}) p<0.002$ \\
\hline Agreeableness lo quartile & $33 \%$ & $26 \%$ & $22 \%$ & $19 \%$ & \\
\hline Hardy Personality hi quartile & $23 \%$ & $31 \%$ & $2 \%$ & $44 \%$ & $38.37(6 \mathrm{df}) p<0.0000$ \\
\hline Hardy Personality lo quartile & $33 \%$ & $26 \%$ & $22 \%$ & $19 \%$ & \\
\hline Depression hi quartile & $29 \%$ & $25 \%$ & $30 \%$ & $17 \%$ & $51.02(6 \mathrm{df}) p<0.0000$ \\
\hline Depression lo quartile & $24 \%$ & $31 \%$ & $2 \%$ & $43 \%$ & \\
\hline Self-Esteem hi quartile & $24 \%$ & $33 \%$ & $4 \%$ & $39 \%$ & $64.35(6 \mathrm{df}) p<0.0000$ \\
\hline Self-Esteem lo quartile & $27 \%$ & $21 \%$ & $35 \%$ & $17 \%$ & \\
\hline Burnout Scales hi quartile & $32 \%$ & $25 \%$ & $35 \%$ & $8 \%$ & $94.47(6 \mathrm{df}) p<0.0000$ \\
\hline Burnout Scales lo quartile & $19 \%$ & $20 \%$ & $4 \%$ & $57 \%$ & \\
\hline Work-Life Stress hi quartile & $30 \%$ & $25 \%$ & $30 \%$ & $15 \%$ & $50.33(6 \mathrm{df}) p<0.0000$ \\
\hline Work-Life Stress lo quartile & $19 \%$ & $36 \%$ & $4 \%$ & $41 \%$ & \\
\hline Nursing Values hi quartile & $24 \%$ & $30 \%$ & $10 \%$ & $36 \%$ & $41.32(6 \mathrm{df}) p<0.0000$ \\
\hline Nursing Values lo quartile & $33 \%$ & $21 \%$ & $30 \%$ & $16 \%$ & \\
\hline
\end{tabular}

Method used: K-means cluster analysis (SPSS-16), specifying five, then four, then three clusters in separate analyses, using factor scores from the principal components analysis shown in Table 3. The finally chosen, four-groups solution (using 11 of the 13 variables in the principal components analysis) maximized average significance differences between groups on the selected variables, listed above. 
Table 6. Four Types of Nurses.

\begin{tabular}{|c|c|}
\hline Four Kinds of Nurses & \\
\hline Group $A(N=79)$ & $\begin{array}{l}\text { "The Soldiers": medium scores on most measures; some burnout; fewer intentions } \\
\text { to leave nursing, but more work-life stress; somewhat lower scores on agreeable } \\
\text { personality, and lower scores on nursing values scale. }\end{array}$ \\
\hline Group B $(N=54)$ & $\begin{array}{l}\text { "Cheerful Professionals": higher job rank; more extraverted; more agreeable; better } \\
\text { self-esteem; not depressed; few plans to leave nursing; medium-to-low scores on } \\
\text { neuroticism and depression; good self-esteem; middle range hardy personality scale } \\
\text { score; somewhat higher attachment to core nursing values. }\end{array}$ \\
\hline Group $C(N=20)$ & $\begin{array}{l}\text { "Highly Stressed, Potential Leavers": high levels of depression and neuroticism; } \\
\text { poor self-esteem; less extraverted; low "hardy personality" profiles; experiencing } \\
\text { work-life stress; somewhat lesser attachment to core nursing values. }\end{array}$ \\
\hline Group $D(N=39)$ & $\begin{array}{l}\text { "High Achievers, Strong and Stable": higher job rank; more extraverted; lower } \\
\text { scores on neuroticism and depression measures; higher scores on hardiness and } \\
\text { self-esteem; less work-life stress; less burnout; higher nursing values profile. }\end{array}$ \\
\hline
\end{tabular}

\section{Discussion of Findings}

First of all, the method of obtaining nurses for our study group using snowball sampling has located an enthusiastic and co-operative group of nurses, who are unique by virtue of the non-random sampling method employed, but who nevertheless manifested many of the characteristics of prior studies which have used random sampling. We anticipated that beginning our network or snowball sample with relatively senior, successful professional nurses might mean that we would miss highly stressed nurses described in previous work in Europe and North America. This has proved not to be the case, and we have identified a sub-group of highly stressed nurses who do anticipate leaving their chosen profession. Nevertheless, we have a sample strongly weighted towards nurses who are both successful and senior in their profession. Hypothetically, a fully representative sample would identify a significant proportion of nurses who experience stress in their profession, and who are leaving nursing in greater numbers, including those being recruited to degree and training courses who are experiencing increasing stress, as nurse-patient ratios worsen.

The Nursing Values Scale (NVS) measuring acceptance of the 6Cs of nursing developed in this study has internal reliability, and some evidence of face validity in terms of its statistically significant correlations. We retained it in the component and cluster analyses not for its predictive power, which as a variable on its own is relatively weak; but because of our personal interest in this scale. It does in fact form part of a variable set which includes Hardy Personality, Extraversion (higher), Self-Esteem (higher), and Neuroticism (lower). On its own the NVS does not significantly predict "intention to leave nursing" when the effects of psychological variables are controlled for. Nevertheless, the NVS is a significant marker for two of the groups emerging from cluster analysis: the "High Achievers" group score highly on the NVS, while the "Highly Stressed" group who contemplate leaving nursing, have lower NVS scores.

We argue that enhancing core nursing values is an important facet of nurse training, as Day et al. (2017) have advocated: internalizing and trying to adhere to such values may be ego-enhancing, and act as a buffer when professional stressors are faced (Gottlieb 2013). Disenchantment with nursing, in the absence of adherence to higher values may be part of the "malaise syndrome" which in turn results in poorer nursing care, with increased rates of patient morbidity and mortality (Aiken et al. 2008; Griffiths et al. 2016).

But the causes of nursing stress, for example, in the United Kingdom, must once again be emphasized: poorly-funded health systems and poor staff-patient ratios result from government policies which leave hospitals chronically underfunded (Marsh 2018).

Burnout (as measured by Maslach's frequently used scale) was certainly a feature of the stress and malaise in this group of nurses. The three sub-scales separately, and combined in a single scale, 
were part of a personal profile in which stress and depression were associated with an intention to leave. Directions of cause are difficult to adduce, however, and only longitudinal work can clarify this. The same observation can be made of the Work-Life Balance stress measure. Some nurses in this sample clearly feel highly stressed by the ways which work impinges on their enjoyment of home life, or vice versa.

But nurses who are identified as having a Hardy Personality do not generally report such stress. Since we do not have a matched comparison sample of non-nurses, we are unable to show whether our cohort of nurses have significantly less favorable levels of depression, poor self-esteem, personality problems, and work and home-life related stress compared with other professional women. We can conclude, however, that within our sample we have identified a sub-group of nurses who are often very depressed in relation to, and perhaps resulting from, the stresses they perceive or experience in their lives and professional roles. Once we have identified such a group, we have an ethical obligation to help them as much as possible, including the use of a peer-counselling model.

Is having a hardy personality an inherent quality of an individual, from childhood onwards-as are some of the Big 5 personality dimensions measured? Should recruits to potentially stressful professional roles be screened for their "hardy personality" profiles? Pre-screening potential recruits to the nursing profession in order to exclude them (e.g., Swider and Zimmerman 2010) is not something that we would countenance, although broad screening of potential nurses when there are more applicants than degree course places may occur.

Work in this field suggests that a major determinant of success in training is the candidate's value commitment to their chosen profession (Traynor et al. 2017). Given this, we advocate that professional educators should develop the personal (and personality) strengths of nurses accepted for training. Alongside socialization in fundamental nursing values, educators should also promote ongoing programs of social support both before and after graduation (Cortese et al. 2010; Düchting 2015). As Welby (2016) has argued, valuing nurses requires the fostering and support of nurses' professional value systems as well as building their professional strengths. Additional strategies such as increasing "mindfulness" (Galante et al. 2017) may also enhance emotional well-being and endurance in professional students. A variety of approaches to problems of burnout deserve to be tested, including cognitive-behavioral counselling (Lloyd et al. 2013). Nurses' spiritual values may be another aspect of a nursing professional's identity which is worth exploring, and supporting (Ross et al. 2014).

Programs exist for promoting "emotional intelligence" and "emotional resilience" in nurses prior to and following their graduation (Montes-Berges and Augusto 2007; Rego et al. 2010; Grant and Kinman 2013; Sharon and Grinberg 2018), and these approaches could also promote (or build on) nurses" "hardy personality". Nursing education, and post-graduate professional support needs to be "strength-based" (Gottlieb 2013; Gottlieb and Gottlieb 2017), and nursing educators could have a crucial role in providing career-long support for their graduates which includes fostering both hardiness and emotional resilience (McSherry et al. 2012). These are important areas for future research, policy development, and social change.

This research employs the approach of Critical Realism (CR), which differs from earlier social research models in significant ways. The CR study begins with a value-based description of ontology, an assertion that there frequently exists within a social structure a hidden but powerful form of alienation, an idea based on Bhaskar's (2002) development of Marxian ideas. At base a crucial area of Absence is defined and identified, which existing power structures usually ignore. For nurses, the crucial Absence we frame in the following proposition:

The majority of nurses are dedicated to caring roles which involve important value commitments, as well as dedication to professional excellence. Yet nurses are not adequately valued or rewarded by the communities and institutions they serve. All too often their welfare and work are devalued in a variety of ways - in modern Britain, for example, by making nurse-patient ratios so unfavorable, that nurses struggle to offer an adequate service. They must soldier on or leave. Only the strongest, 
the most dedicated, survive. This continued struggle of nurses to break from the bonds of professional alienation is largely absent in the public discourse concerning health reform.

From the review of both the clinical and the political debate surrounding nursing, we find little emphasis on the dedication of nurses, and their willingness to "soldier on". The single exception, in our experience is the organization dedicated to the professional excellence of nursing in the UK: The Royal College of Nurses, which offers to politicians and professionals a flow of well-written, finely argued, and well-researched reports (e.g., Ball and Pike 2009; Ball and Catton 2011; Ball and Royal College of Nursing Research Team 2005; Ball et al. 2014; RCN 2017). Official government silence in the face of these reports, and the parallel clinical research showing that worsening nurse-patient ratios are a direct cause of increases in patient mortality and morbidity in England (Aiken et al. 2014; Ball et al. 2014; Griffiths et al. 2016) are ignored by politicians and policy-makers, until another major crisis-usually an excess of patient deaths-emerges. resulting in an official enquiry (e.g., Francis 2013) whose recommendations are then largely ignored, with continued public underfunding of health care, and worsening of nurse-patient ratios (Grierson 2017).

This value-based idea of the exploitation and alienation of nurses we held at the beginning of this research and have reviewed the literature and undertaken data analysis in order to elaborate and support our initial value-based position on this alienation, exploring how dialogue might increase the consciousness of nurses about their oppression, in the CR process of morphogensisis (Archer 2007).

The present study was not an empirical or hypothesis-testing exercise, but rather attempted to use complex data analysis methodologies which lead, heuristically within an overall qualitative design, to the humanizing description not of relationships between data (things), but between groups of people (humans) working together for the same goal, bound together by a set of higher order nursing values.

\section{Conclusions}

Although statistical methods have been used in analyzing data, this is essentially a qualitative study, using statistical modelling within the qualitative framework of a critical realist approach, in the study of a specially selected group of nurses. However, the standard rules for analysis of statistical data have been carefully followed in the exercise of generating correlations, exploring the primacy of variables through regression analysis, then the grouping of variables, and then of individuals. The heuristic procedure has been one of data reduction, minimizing the number of variables required to produce a meaningful typology of individuals.

This approach has been relatively successful in producing four types of individuals, with nursing careers ranging from the very successful "hardy personality" career nurses, who can cope successfully with a variety of professional and personal challenges, with two groups of successful nurses "soldiering on" in the middle range, through to a marginal group who are clearly not coping and need psychological, social, and professional support-help which they were not currently receiving.

In the next phase of this longitudinal study we will report on the development and outcomes of a co-counselling model, in which 20 successful career nurses offer what help and support they can to their struggling colleagues, whom we have identified in this study.

The limitations of our work must be stressed. First of all, our sample is relatively small, and replication with a larger group of nurses using a different method of sampling (e.g., random sampling) would be welcome, to see if our four-level typology can be replicated, and whether the proportion of nurses "intending to leave" would be greater in a more random sample. We do not have a control or contrast group of professional women in non-nursing roles, so we are not certain that it is the pressures of a nursing career which are causing psychological distress in the women in our sample. But we are certainly aware of the multiple stressors which face women who try and achieve senior positions in various employment sectors, including those concerned with human service careers (Bagley et al. 2018).

Although the correlations which emerged in the analysis of the variables measured are compatible with those of previous studies, we remain disappointed that the correlations in our own and in previous 
work rarely explain more than half of the shared variance of any two variables (or set of variables). This implies both complexity of interacting influences on personal adjustment and role performance; and a degree of imperfection in the ability of standardized instruments to capture fully the concepts or domains they purport to measure.

Directions of cause are often also difficult to adduce, in our own and in previous work. Longitudinal work may be able to clarify this.

Author Contributions: The three authors shared equal responsibility in the conceptualization, conduct of research, and the writing of this paper.

Funding: This research was not supported by any external funding.

Ethical Approval: The research was conducted according to the ethical principles of the Declaration of Helsinki, and received the ethical approval of the National Health Service (England) for research undertaken outside of health settings, with non-clinical subjects (Ref: NHS NW16.37).

Conflicts of Interest: The three authors declare no conflict of interest. None of them is professionally concerned with the current delivery of health care, or with nurse education. Two of the authors have been Registered Nurses with professional responsibilities, in the previous century.

\section{References}

Adriaenssens, Jef, Veronique De Gucht, and Stan Maes. 2015. Determinants and prevalence of burnout in emergency nurses: A systematic review of 25 years of research. International Journal of Nursing Studies 52: 649-61. [CrossRef] [PubMed]

Aiken, Linda H., Sean P. Clarke, Douglas M. Sloane, Eileen T. Lake, and Timothy Cheney. 2008. Effects of hospital care environment on patient mortality and nurse outcome. Journal of Nursing Administration 38: 223-29. [CrossRef] [PubMed]

Aiken, Linda H., Douglas M. Sloane, Luk Bruyneel, Koen Van den Heede, Peter Griffiths, Reinhard Busse, and Marianna Diomidous. 2014. Nurse staffing and education and hospital mortality in nine European countries: A retrospective observational study. The Lancet 383: 1824-30. [CrossRef]

Akerboom, Simone, and Stan Maes. 2006. Beyond demand and control: The contribution of organizational risk factors in assessing the psychological well-being of health care employees. Work and Stress 20: 21-36. [CrossRef]

Alderson, Priscilla. 2013. Childhoods Real and Imagined: An Introduction to Critical Realism. Abingdon: Routledge.

Alderson, Priscilla. 2015. The Politics of Childhoods Real and Imagined: Volume 2 Practical Applications of Critical Realism and Childhood Studies. Abingdon: Routledge.

Allmark, Peter, and Katarzyna Machaczek. 2018. Realism and Pragmatism in a mixed methods study. Journal of Advanced Nursing 74: 1301-9. [CrossRef] [PubMed]

Anderson, Marie, Xavier Parent-Rocheleau, and Brian Mishara. 2015. Critical review on suicide among nurses. Crisis 36: 91-101. [CrossRef] [PubMed]

Archer, Margaret S. 2007. Making Our Way through the World: Human Reflexivity and Social Mobility. Cambridge: Cambridge University Press.

Bagley, Christopher, Alice Sawyerr, and Mahmoud Abubaker. 2016. Dialectic Critical Realism: Grounded values and reflexivity in social science research. Advances in Applied Sociology 6: 400-19. [CrossRef]

Bagley, Christopher Adam, Mahmoud Abubaker, and Afroze Shahnaz. 2018. Woman and management: A conceptual review, with a focus on Muslim women in management roles in Western and in Muslim-majority countries. Open Journal of Business and Management 6: 485-507. [CrossRef]

Bailey, Daniel. 2012. Sociological classification and cluster analysis. In Cluster Analysis. Edited by Kenneth D. Byrne and Emma Uprichard. London: Sage, vol. 2, pp. 200-12.

Bakker, Arnold B., Karen I. Van Der Zee, Kerry A. Lewig, and Maureen F. Dollard. 2006. The relationship between the big five personality factors and burnout: A study among volunteer counselors. The Journal of Social Psychology 146: 31-50. [CrossRef]

Ball, Jane, and Howard Catton. 2011. Planning nurse staffing: Are we willing and able? Journal of Research in Nursing 16: 551-58. [CrossRef] 
Ball, Jane, and Geoff Pike. 2009. Past Imperfect, Future Tense-Nurses' Employment and Morale in 2009. London: Royal College of Nursing.

Ball, Jane, and Royal College of Nursing Research Team. 2005. Maxi Nurses: Advanced and Specialist Nursing Roles: Results from a Survey of RCN Members in Advanced and Specialist Nursing Roles. London: Royal College of Nursing. London: Royal College of Nursing.

Ball, Jane E., Trevor Murrells, Anne Marie Rafferty, Elizabeth Morrow, and Peter Griffiths. 2014. 'Care left undone' during nursing shifts: Associations with workload and perceived quality of care. BMJ Health and Safety 23: 116-25. [CrossRef] [PubMed]

Bartone, Paul T., Robert R. Roland, James J. Picano, and Thomas J. Williams. 2008. Psychological hardiness predicts success in US Army Special Forces candidates. International Journal of Selection and Assessment 16: 78-81. [CrossRef]

Benishek, Lois A., and Frederick G. Lopez. 2001. Development and initial validation of a measure of academic hardiness. Journal of Career Assessment 9: 333-52. [CrossRef]

Bhaskar, Roy. 2002. From Science to Emancipation: Alienation and Enlightenment. Abingdon: Routledge.

Boyar, Scott L., Jon C. Carr, Donald C. Mosley Jr., and Charles M. Carson. 2007. The development and validation of scores on perceived work and family demand scales. Educational and Psychological Measurement 67: 100-15. [CrossRef]

Browning, Laura, Carey S. Ryan, Scott Thomas, Martin Greenberg, and Susan Rolniak. 2007. Nursing specialty and burnout. Psychology, Health and Medicine 12: 248-54. [CrossRef] [PubMed]

Bruck, Carly S., and Tammy D. Allen. 2003. The relationship between big five personality traits, negative affectivity, type A behavior, and work-family conflict. Journal of Vocational Behavior 63: 457-72. [CrossRef]

Bruyneel, Luk, Tom Thoelen, Jef Adriaenssens, and Walter Sermeus. 2016. Emergency room nurses' pathway to turnover intention: A moderated serial mediation analysis. Journal of Advanced Nursing 73: 930-42. [CrossRef]

Byrne, Kenneth D., and Emma Uprichard. 2012. Data mining with classification. In Cluster Analysis. Edited by Kenneth D. Byrne and Emma Uprichard. London: Sage, vol. 4, pp. 10-25.

Caetano, Ana. 2015. Defining personal reflexivity: A critical reading of Archer's approach. European Journal of Social Theory 18: 60-75. [CrossRef]

Clarke, Chris. 2014. Promoting the 6Cs of nursing in patient assessment. Nursing Standard 28: 52. [CrossRef]

Coomber, Billie, and K. Louise Barriball. 2007. Impact of job satisfaction components on intent to leave and turnover for hospital-based nurses: A review of the research literature. International Journal of Nursing Studies 44: 297-314. [CrossRef]

Cortese, Claudio G., Lara Colombo, and Chiara Ghislieri. 2010. Determinants of nurses' job satisfaction: The role of work-family conflict, job demand, emotional charge and social support. Journal of Nursing Management 18: 35-43. [CrossRef] [PubMed]

Cummings, Jane, and Vivienne Bennett. 2012. Compassion in Practice. Nursing Midwifery and Care Staff. Our Vision and Strategy. Available online: www.england.nhs.uk/wp-content/uploads/2012/12/compassion-inpractice.pdf (accessed on 20 March 2018).

Day, Lisa, Scott R. Ziehm, Martha A. Jessup, Pattie Amedro, Carol Dawson-Rose, Anne Derouin, Betsy Babb Kennedy, Sally Manahan, Abby Luck Parish, and Rachel Naomi Remen. 2017. The power of nursing: An innovative course in values clarification and self-discovery. Journal of Professional Nursing 33: 267-70. [CrossRef] [PubMed]

De Boer, Jacoba Coby, Anja Lok, Ellen van't Verlaat, Hugo J. Duivenvoorden, Arnold B. Bakker, and Bert J. Smit. 2011. Work-related critical incidents in hospital-based health care providers and the risk of post-traumatic stress symptoms, anxiety, and depression: A meta-analysis. Social Science E Medicine 73: 316-26.

Dewe, Philip, and Cary L. Cooper. 2017. Work, Stress and Coping. London: Sage.

Düchting, Maren. 2015. Improving the Work-Life Balance of Registered Nurses. Norderstedt: Grin Verlag.

Edwards, Deborah. 2001. A stepwise multivariate analysis of factors that contribute to stress for mental health nurses working in the community. Journal of Advanced Nursing 36: 805-13. [CrossRef] [PubMed]

Francis, Robert. 2013. Report of the Mid Staffordshire NHS Foundation Trust Public Inquiry. Available online: http:/ / www.midstaffspublicinquiry.com/report (accessed on 19 September 2016). 
Galante, Julieta, Géraldine Dufour, Maris Vainre, Adam P. Wagner, Jan Stochl, Alice Benton, Neal Lathia, Emma Howarth, and Peter B. Jones. 2017. A mindfulness-based intervention to increase resilience to stress in university students (the Mindful Student Study): A pragmatic randomised controlled trial. The Lancet Public Health 3: e72-81. [CrossRef]

Garrosa, Eva, Bernardo Moreno-Jimenez, Youxin Liang, and Jose Luis Gonzalez. 2008. The relationship between socio-demographic variables, job stressors, burnout, and hardy personality in nurses: An exploratory study. International Journal of Nursing Studies 45: 418-27. [CrossRef] [PubMed]

Gottlieb, Laurie N. 2013. Strengths-Based Nursing Care: Health and Healing the Person and Family. New York: Springer.

Gottlieb, Laurie N., and Bruce Gottlieb. 2017. Strengths-based nursing: A process for implementing a philosophy into practice. Journal of Family Nursing 23: 319-40. [CrossRef] [PubMed]

Grant, Louise Jane, and Gail Kinman. 2013. The Importance of Emotional Resilience for Staff in the Helping Professions: Developing an Emotional Curriculum. Bedford: University of Bedfordshire Higher Education Academy.

Grierson, Jamie. 2017. NHS hasn't improved enough since Mid Staffs, says inquiry lawyer. The Guardian Online, February 12.

Griffiths, Peter, Jane Ball, Trevor Murrells, Simon Jones, and Anne Marie Rafferty. 2016. Registered nurse, healthcare support worker, medical staffing levels and mortality in English hospital trusts: A cross-sectional study. BMJ Open 6: e008751. [CrossRef] [PubMed]

Hacking, James. 2012. How 'rational' are 'kinds' of 'sexual orientation'? In Cluster Analysis. Edited by Kenneth D. Byrne and Emma Uprichard. London: Sage, vol. 1, pp. 221-37.

Hayman, Jeremy. 2005. Psychometric assessment of an instrument designed to measure work life balance. Research and Practice in Human Resource Management 13: 85-91.

Hayman, Jeremy R. 2009. Flexible work arrangements: Exploring the linkages between perceived usability of flexible work schedules and work/life balance. Community, Work and Family 12: 327-38. [CrossRef]

Heckathorn, Douglas D. 2011. Comment: Snowball versus respondent-driven sampling. Sociological Methodology 41: 355-66. [CrossRef] [PubMed]

Heinen, Maud M., Theo van Achterberg, René Schwendimann, Britta Zander, Anne Matthews, Maria Kózka, and Anneli Ensio. 2013. Nurses' intention to leave their profession: A cross sectional observational study in 10 European countries. International Journal of Nursing Studies 50: 174-84. [CrossRef] [PubMed]

Hillege, Sanne L., Eddy F. J. M. Brand, Eva A. Mulder, Robert R. J. M. Vermeiren, and Lieke Domburgh. 2017. Serious juvenile offenders: Classification into subgroups based on static and dynamic characteristics. Child and Adolescent Psychiatry and Mental Health 11: 67. [CrossRef] [PubMed]

Jang, Kerry L., W. John Livesley, and Philip A. Vemon. 1996. Heritability of the big five personality dimensions and their facets: A twin study. Journal of Personality 64: 577-92. [CrossRef] [PubMed]

Judge, Timothy A., Daniel Heller, and Michael K. Mount. 2002. Five-factor model of personality and job satisfaction: A meta-analysis. Journal of Applied Psychology 27: 530-54. [CrossRef]

Kandola, Damanpreet, Davina Banner, Sheila O'Keefe-McCarthy, and Debbie Jassal. 2014. Sampling methods in cardiovascular nursing research: An overview. Canadian Journal of Cardiovascular Nursing 24: 15-18. [PubMed]

Knight, Robert G., Sheila Williams, Rob McGee, and Susan Olaman. 1997. Psychometric properties of the Center for Epidemiologic Studies Depression Scale (CES-D) in a sample of women in middle life. Behavior Research $\mathcal{E}$ Therapy 35: 373-80.

Kobasa, Suzanne C., Salvatore R. Maddi, and Stephen Kahn. 1982. Hardiness and health: A prospective study. Journal of Personality and Social Psychology 42: 168-78. [CrossRef]

Kõlves, Kairi, and Diego De Leo. 2013. Suicide in medical doctors and nurses: Analysis of the Queensland Suicide Register. The Journal of Nervous and Mental Diseases 201: 987-90. [CrossRef]

Langelaan, Saar, Arnold B. Bakker, Lorenz J. P. Van Doornen, and Wilmar B. Schaufeli. 2006. Burnout and work engagement: Do individual differences make a difference? Personality and Individual Differences 40: 521-32. [CrossRef]

Li, Jian, Michael Galatsch, Johannes Siegrist, Bernd Hans Müller, Hans Martin Hasselhorn, and European NEXT Study Group. 2011. Reward frustration at work and intention to leave the nursing profession-Prospective results from the European longitudinal NEXT study. International Journal of Nursing Studies 48: 628-35. [CrossRef] [PubMed] 
Lloyd, Joda, Frank W. Bond, and Paul E. Flaxman. 2013. The value of psychological flexibility: Examining psychological mechanisms underpinning a cognitive behavioural therapy intervention for burnout. Work E Stress 27: 181-99.

Maben, Jill, Sue Latter, and Jill Macleod Clark. 2006. The theory-practice gap: Impact of professional-bureaucratic work conflict on newly-qualified nurses. Journal of Advanced Nursing 55: 465-77. [CrossRef]

Marsh, Sarah. 2018. More nurses needed to avoid new Mid Staffs-style scandal, says RCN. The Guardian Online, February 5.

Maslach, Christina, and Susan E. Jackson. 1986. Maslach Burnout Inventory. Palo Alto: Consulting Psychologists Press.

Maslach, Christina, Wilmar B. Schaufeli, and Michael P. Leiter. 2001. Job burnout. Annual Review of Psychology 52: 397-422. [CrossRef] [PubMed]

Maslach, Christina, Susan E. Jackson, Michael P. Leiter, Wilmar B. Schaufeli, and Richard L. Schwab. 2006. Maslach Burnout Inventory Manual, 5th ed. Palo Alto: Consulting Psychologists Press.

McCrae, Robert R., Paul T. Costa, Margarida Pedroso de Lima, António Simões, Fritz Ostendorf, Alois Angleitner, and Iris Marušić. 1999. Age differences in personality across the adult life span: Parallels in five cultures. Developmental Psychology 35: 466-80. [CrossRef] [PubMed]

McCrae, Robert R., Shinji Yamagata, Kerry L. Jang, Rainer Riemann, Juko Ando, Yutaka Ono, Alois Angleitner, and Frank M. Spinath. 2008. Substance and artifact in the higher-order factors of the Big Five. Journal of Personality and Social Psychology 95: 442-60. [CrossRef]

McEvoy, Phil, and David Richards. 2003. Critical realism: A way forward for evaluation research in nursing? Journal of Advanced Nursing 43: 411-20. [CrossRef]

McSherry, Robert, Paddy Pearce, Karen Grimwood, and Wilfred McSherry. 2012. The pivotal role of nurse managers, leaders and educators in enabling excellence in nursing care. Journal of Nursing Management 20: 7-19. [CrossRef]

Mokhtarian, Patricia, David Ory, and Xinyu Cao. 2012. Shopping-related attitudes: A factor analytical and cluster analysis. In Cluster Analysis. Edited by Kenneth D. Byrne and Emma Uprichard. London: Sage, vol. 3, pp. 157-70.

Montes-Berges, Bernard, and Jean-Marc Augusto. 2007. Exploring the relationship between perceived emotional intelligence, coping, social support and mental health in nursing students. Journal of Psychiatric and Mental Health Nursing 14: 163-71. [CrossRef]

NMC. 2015. Standards and Competence for Registered Nurses. London: Nursing and Midwifery Council.

Parlour, Randal, and Brendan McCormack. 2012. Blending critical realist and emancipatory practice development methodologies: Making critical realism work in nursing research. Nursing Inquiry 19: 308-21. [CrossRef]

Peterson-Graziose, Virginia, Jennifer Bryer, and Maria Nikolaidou. 2013. Self-esteem and self-efficacy as predictors of attrition in associate degree nursing students. Journal of Nursing Education 52: 351-54. [CrossRef]

Pisanti, Renato, Caterina Lombardo, Fabio Lucidi, Cristiano Violani, and David Lazzari. 2013. Psychometric properties of the Maslach Burnout Inventory for human services among Italian nurses: A test of alternative models. Journal of Advanced Nursing 69: 697-707. [CrossRef]

Radloff, Lenore Sawyer. 1977. The CES-D scale: A self report depression scale for research in the general population. Applied Psychological Measurement 1: 385-40. [CrossRef]

RCN. 2017. Principles of Nursing Practice. London: The Royal College of Nursing.

Rego, Arménio, Lucinda Godinho, Anne McQueen, and Miguel P. Cunha. 2010. Emotional intelligence and caring behaviour in nursing. The Service Industries Journal 30: 1419-37. [CrossRef]

Revans, Reginald W. 1996. The hospital as a human system. Reprinted from Physics in Medicine and Biology, Vol. 7, No. 2, pp. 147-155, October 1962. Bulletin of the New York Academy of Medicine 73: 418-26. [PubMed]

Rich, Victoria L., and Alexander R. Rich. 1987. Personality hardiness and burnout in female staff nurses. Journal of Nursing Scholarship 19: 63-66. [CrossRef]

Ross, Linda, Rene Van Leeuwen, Donia Baldacchino, Tove Giske, Wilfred McSherry, Aru Narayanasamy, Carmel Downes, Paul Jarvis, and Annemiek Schep-Akkerman. 2014. Student nurses perceptions of spirituality and competence in delivering spiritual care: a European pilot study. Nurse Education Today 34: 697-702. [CrossRef] [PubMed]

Sadler, Georgia Robins, Hau-Chen Lee, Rod Seung-Hwan Lim, and Judith Fullerton. 2010. Recruitment of hard-to-reach population subgroups via adaptations of the snowball sampling strategy. Nursing $\mathcal{E}$ Health Sciences 12: 369-74. 
Sawyerr, Alice Akoshia Ayikaaley, and Christopher Adam Bagley. 2017. Equality and Ethnic Identities: Studies of Self-Concept, Child Abuse and Education in a Changing English Culture. Leiden: Brill I Sense Education Series.

Schiller, Catharine J. 2016. Critical realism in nursing: An emerging approach. Nursing Philosophy 17: 88-102. [CrossRef] [PubMed]

Sharon, Dganit, and Keren Grinberg. 2018. Does the level of emotional intelligence affect the degree of success in nursing studies? Nurse Education Today, January 30.

Sibandze, Beate T., and Katerina N. Scafide. 2017. Among nurses, how does education level impact professional values? A systematic review. International Nursing Review 65: 65-77. [CrossRef] [PubMed]

Smeltzer, Suzanne C., Mary Ann Cantrell, Nancy C. Sharts-Hopko, Mary Ann Heverly, Amanda Jenkinson, and Serah Nthenge. 2016. Psychometric analysis of the Work/Life Balance self-assessment scale. Journal of Nursing Measurement 24: 5-14. [CrossRef]

Soto, Christopher J., Oliver P. John, Samuel D. Gosling, and Jeff Potter. 2011. Age differences in personality traits from 10 to 65: Big Five domains and facets in a large cross-sectional sample. Journal of Personality and Social Psychology 100: 330-40. [CrossRef] [PubMed]

Spurlock, Darrell. 2017. Beyond $p<0.05$ : Toward a Nightingalean perspective on statistical significance for nurse education. Journal of Nursing Education 66: 453-55.

Stephenson, Jo. 2014. NHS England to roll out '6Cs' nursing values to all health service staff. Nursing Times, April 23.

Sturm, Bonnie A., and Jane C. Dellert. 2016. Exploring nurses' personal dignity, global self-esteem and work satisfaction. Nursing Ethics 23: 384-400. [CrossRef] [PubMed]

Swider, Brian W., and Ryan D. Zimmerman. 2010. Born to burnout: A meta-analytic path model of personality, job burnout, and work outcomes. Journal of Vocational Behavior 76: 487-506. [CrossRef]

Törnroos, Maria, Mirka Hintsanen, Taina Hintsa, Markus Jokela, Laura Pulkki-Råback, Nina Hutri-Kähönen, and Liisa Keltikangas-Järvinen. 2013. Associations between Five-Factor Model traits and perceived job strain: A population-based study. Journal of Occupational Health Psychology 18: 492-510. [CrossRef] [PubMed]

Traynor, Marian, Despina Galanouli, Martin Roberts, Lawrence Leonard, and Thomas Gale. 2017. Identifying applicants suitable to a career in nursing: A value-based approach to undergraduate selection. Paper presented at International Nursing and Midwifery Conference on Professional Values-The Key to Effective, Safe and High-Quality Person-Centred Care, London, UK, March 1.

Triggle, Nicholas. 2018. NHS Hemorrhaging Nurses, as 33,000 Leave Each Year. British Broadcasting Corporation. Available online: https:/ / www.bbc.co/news/health-42653542 (accessed on 1 March 2018).

Valerio, Melissa A., Natalia Rodriguez, Paula Winkler, Jaime Lopez, Meagen Dennison, Yuanyuan Liang, and Barbara J. Turner. 2016. Comparing two sampling methods to engage hard-to-reach communities in research priority setting. BMC Medical Research Methodology 16: 146. [CrossRef]

Van Bogaert, Peter, Sean Clarke, Karel Vermeyen, Herman Meulemans, and Paul Van de Heyning. 2009a. Practice environments and their associations with nurse-reported outcomes in Belgian hospitals. International Journal of Nursing Studies 46: 55-65. [CrossRef]

Van Bogaert, Peter, Herman Meulemans, Sean Clarke, Karel Vermeyen, and Paul Van de Heyning. 2009b. Hospital nurse practice environment, burnout, job outcomes and quality of care: Test of a structural equation model. Journal of Advanced Nursing 65: 2175-85. [CrossRef]

Walsh, Denis, and Kerry Evans. 2014. Critical realism: An important theoretical perspective for midwifery research. Midwifery 30: e1-e6. [CrossRef]

Welby, Jane. 2016. Selecting the Right Candidates with the Right Values for Nursing. Ph.D. thesis, University of Bradford, Bradford, UK.

Williams, Lynne, Jo Rycroft-Malone, and Christopher R. Burton. 2017. Bringing critical realism to nursing practice: Roy Bhaskar's contribution. Nursing Philosophy 18: e12130. [CrossRef] [PubMed]

Wilson, Valerie, and Brendan McCormack. 2006. Critical realism as emancipatory action: The case for realistic evaluation in practice development. Nursing Philosophy 7: 45-57. [CrossRef] [PubMed]

Yilmaz, Sinem, Bart Van de Putte, and Peter AJ Stevens. 2017. Work-family conflict: Comparing the experiences of Turkish and native Belgian women. Community, Work and Family 2017: 1-17. [CrossRef]

(C) 2018 by the authors. Licensee MDPI, Basel, Switzerland. This article is an open access article distributed under the terms and conditions of the Creative Commons Attribution (CC BY) license (http:/ / creativecommons.org/licenses/by/4.0/). 